\title{
Impact Of Collaborative Groups Versus Individuals In Undergraduate Inquiry-Based Astronomy Laboratory Learning Exercises
}

\author{
Kendra J. Sibbernsen, Metropolitan Community College, USA
}

\begin{abstract}
A mixed-method quasi-experimental study was designed to determine how 130 undergraduates in an introductory astronomy survey course laboratory changed their understanding of scientific inquiry working as individuals in relative isolation compared to working in small, collaborative learning groups when using specially designed astronomy curricula based on a backwards faded scaffolding approach (Slater, Slater, \& Lyons, 2010). The results of this two-group comparison study were determined by examining the change in responses from the pretest to the posttest administration of the Views of Scientific Inquiry (VOSI) survey (Schwartz, Lederman, \& Lederman, 2008), the increase in scores on laboratory exercises, and analysis of field notes from the instructor. Analysis suggests that all students increased their understanding of scientific inquiry and astronomy when using the specially designed course materials regardless if the students were working in groups or individually in the learning laboratories. However, qualitative analysis yields further insight that there exists a qualitative difference in the complexity of research questions students working in groups elect to pursue over those students working independently.
\end{abstract}

Keywords: Astronomy Education, Science Teaching, Collaborative Group Learning, Laboratory Instruction, Nature Of Science

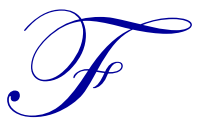

raknoi (2001) estimated that at least 250,000 undergraduate non-science majors enroll in an introductory astronomy survey course each year. For many of these students, this course satisfies a typical general education requirement for physical science course credits, and it is often the last science course they take in their college experience. The critical positioning of this course extends beyond increasing the scientific literacy of undergraduate non-science majors: An estimated $40 \%$ of introductory science course enrollees eventually become licensed teachers (Lawrenz, Huffman, \& Appeldoorn, 2005). These future teachers' knowledge and attitudes regarding science engendered during their basic college physical science courses could have a dramatic impact on generations of children when they are at their most impressionable (Fraknoi, 2001).

A science course with a laboratory experience component serves as one of the long-standing general undergraduate education requirements common to many colleges and universities. Consistent with recommendations of the American Association for the Advancement of Science (1990, 1993), the National Research Council (2005), and the Society of College Science Teachers (1993), one of the objectives frequently included in the description of many of these courses is that a student will understand the nature and processes of scientific inquiry. Given that this intent represents such a universally called for course learning goal, it seems worthwhile to ascertain if particular aspects of the design and implementation of laboratory courses can explicitly meet this objective.

In order to adequately measure students' understanding of scientific inquiry, discipline-based astronomy education researchers first need to define inquiry, identify the important components worth studying, and then use appropriate measuring instruments. This necessity presents a challenge because a widely accepted consensus definition of inquiry has not yet been founded (NRC, 2005; Schwartz et al., 2008). Harwood (2004) has argued that 
the traditional linear scientific method, as it has been taught in schools for many years, is limited, and has even given an incorrect understanding of how contemporary science is actually done. To further illuminate how science is done, Schwartz (2004) examined how a number of cross-disciplinary scientists viewed scientific inquiry, reviewed instruments that were designed to measure an understanding of the nature of science (NOS) and the nature of scientific inquiry (NOSI), and eventually produced an instrument (2008) that compared the sophistication of students' views of scientific inquiry (VOSI) compared to that of the scientists.

The traditional astronomy laboratory exercises have long been criticized as being less than intellectually engaging by frequently asking students to graph an abstract set of provided data, such as the luminosity of stars versus their temperatures, and to confirm concepts discussed earlier in lecture or in their textbook. In an effort to increase the level of student engagement in inquiry, S. Slater led the development of a new set of astronomy laboratory learning activities that purposefully scaffold a student from guided inquiry activities to open inquiry ones and are based on a backwards faded scaffolding (BFS) design (Slater, Slater, \& Shaner, 2008). Preliminary results show the success of these laboratories in supporting students' understanding of the nature of scientific inquiry (Stewart, 2013; Lyons 2011). To examine more deeply the effectiveness of this BFS instructional design, it is valuable to know how students increase their understanding of inquiry individually compared to working in small learning teams. A more complete understanding adds to the growing astronomy education literature based on how to engage students in the "doing" of science. Moreover, a better understanding serves as a valuable precursor to offering astronomy laboratories online where off-campus, place-bound students would most likely be completing the laboratory learning experiences individually.

In response to the needs described above, this study focused on a single research question:

When using specifically designed inquiry-based laboratory activities that scaffold student learning to engage in designing and conducting open inquiry, how do students in an undergraduate astronomy laboratory increase their understanding of inquiry when working individually as compared to working in small, collaborative learning groups?

\section{METHOD}

\section{Participants}

To answer this question, this study adopted a two-group, pretest/posttest quasi-experimental mixed-method design (Slater, Slater, \& Bailey, 2011, p. 36). The sample of students studied was of local age-of-consent and volunteered to participate without compensation. Undergraduates were invited from all of those taking selected introductory astronomy laboratory classes one semester at a Western regional, doctoral-granting, research-extensive university. The demographic data of introductory astronomy students demonstrated a variety of ages and ethnicities, but most were non-minority traditional-aged undergraduates with ages ranging from 18-24.

In this study, the majority of students completed their exercises in small, self-formed, collaborative laboratory groups that constituted one treatment group. A second treatment group was composed of students who completed their inquiry-based laboratory exercises individually. Students were not given a choice as to which treatment group they were assigned.

\section{Procedure}

The two-groups of students were given the Views of Scientific Inquiry (VOSI) survey (Schwartz, Lederman, \& Lederman, 2008), in a pre- and posttest format. For the pretest administration, a total of 131 students responded, and 128 students responded to the posttest administration of the VOSI questionnaire. One out of eight laboratory classes had students complete their exercises individually to compare to those who completed their laboratories in groups of two, three, or four students. The class performing individually had 16 students the first week, but only 12 of these could be paired with the final week as opposed to 25 paired first week/last week scores for the group condition. Likely, some students from the groups did not attend the last week's laboratory, but the criteria for inclusion required that at least two members must be in common from the first week to the last week to 
be paired. Some of these students, therefore, could be missing, and the rest of the group would make up for them because only one score was given per group.

All students in both groups shared the results of their inquiries with the larger class to receive feedback and to give feedback to others. These specially designed exercises tasked students to use and ask research questions of astronomical data available online through National Aeronautics and Space Administration (NASA) sources, Caltech's Jet Propulsion Laboratory (JPL), and other sources and are described extensively elsewhere (Slater, Slater, \& Lyons, 2010; 2011). Each student or student-group needed computer access with a working Internet connection. The students working individually were not isolated from any peer-to-peer interaction.

\section{DATA AND RESULTS}

The version of Schwartz's (2008) VOSI instrument used for this study targeted undergraduate, non-science majoring students enrolled in a liberal arts, general education course that satisfied a curricular distribution requirement for a laboratory-based science course. The student-supplied responses from the pre- and posttests of the VOSI were in the form of qualitative written narratives reviewed and coded using descriptors. These narratives were analyzed and placed into categories of level of understanding to see if a difference could be determined before and after the course. Some common elements in the responses were reported qualitatively in the form of a narrative.

In addition, student artifacts from two different laboratory exercises were chosen for detailed analysis, one at the beginning of the course and one at the end of the course, and were considered functionally equivalent in terms of difficulty and mathematical sophistication needed. The open inquiry component of these exercises included a combination of a research question, data, and analysis by the students. This section was analyzed according to a rubric that focused on inquiry and described in detail elsewhere (Sibbernsen, 2010), and that rubric presented the results as numerical data. In turn, the data were used to analyze differences between the groups.

The qualitative data and the quantitative data were compared to see if they presented similar results. The qualitative data and the quantitative data in this mixed method study were given equal status and were collected concurrently (Johnson \& Onwuegbuzie, 2004).

\section{Qualitative - VOSI Data}

The VOSI questionnaire was administered as a pretest and a posttest to all of the introductory astronomy laboratory students enrolled, but only the data from volunteering students are included in this analysis, which is effectively $100 \%$. These questionnaires were analyzed to determine how students' views of scientific inquiry changed over the course of the semester. For the pretest administration, a total of 131 students responded, and 128 students responded to the posttest administration of the VOSI questionnaire. One out of eight laboratory classes had students complete their exercises individually to compare to those who completed their laboratories in groups. The VOSI pretests and posttests were paired for all students in this class to examine closely their changes in views of scientific inquiry to see if they corresponded to the entire surveyed group. There were 15 VOSI pretests and posttests paired for the individual completion laboratory group. Therefore, 116 students were in the group completion section for the pretest VOSI and 113 for the posttest. Each of the seven questions of the VOSI questionnaire corresponds to a different component of the understanding of inquiry and the nature of how scientists do science. The results of each of these questions are addressed separately, as prescribed by Schwartz, Lederman \& Lederman (2008).

\section{VOSI Question 1}

This first question examined views of activities that scientists do when they "do science." Specifically, students were asked, "What types of activities do scientists (e.g., biologists, chemists, physicists, earth scientists) do to learn about the natural world? Discuss how scientists (biologists, chemists, earth scientists) do their work." 
Table 1: Number Of Responses To Question 1

\begin{tabular}{|c|c|c|c|c|}
\hline Group Completion & $\begin{array}{c}\text { Naïve } \\
\text { n (\% of Total) }\end{array}$ & $\begin{array}{c}\text { Too General } \\
\text { n (\% of Total) }\end{array}$ & Typical Response & Informed View \\
\hline Pretest & $15(13 \%)$ & $44(38 \%)$ & $51(44 \%)$ & $7(6 \%)$ \\
\hline Posttest & $1(1 \%)$ & $25(22 \%)$ & $81(72 \%)$ & $6(5 \%)$ \\
\hline \multicolumn{5}{|l|}{ Individual completion } \\
\hline Pretest & $3(20 \%)$ & $4(27 \%)$ & $6(40 \%)$ & $2(13 \%)$ \\
\hline Posttest & $0(0 \%)$ & $3(20 \%)$ & $11(73 \%)$ & $1(7 \%)$ \\
\hline Frequency of Terms or Phrases Used & & Pretest & Posttest & \\
\hline Experiment & & 76 & 83 & \\
\hline Ask questions & & 15 & 42 & \\
\hline Make hypothesis & & 41 & 35 & \\
\hline Collect/analyze data & & 55 & 52 & \\
\hline Make observations & & 56 & 51 & \\
\hline Scientific method & & 24 & 11 & \\
\hline Test theories & & 26 & 11 & \\
\hline Make conclusions & & 12 & 25 & \\
\hline
\end{tabular}

An example of a naïve response would be, "They do their work by discovering new things by going outside." An example of a response that would be too general would be, "Scientists run tests to answer questions." A typical response for this question includes a description of activities such as, "observe, experiment, ask questions, make hypotheses, collect and analyze data, and draw conclusions." An informed view includes all of the typical responses and also includes such activities as, "collaborate with other scientists and publish in peer-reviewed journals."

\section{VOSI Question 2}

This second question explores the understanding of the scientific distinction between the terms "data" and "evidence." In part (a) of the question, students were asked, "What does the word "data" mean in science?"

Table 2: Number Of Responses To Question 2 (a)

\begin{tabular}{lcc}
\hline \multicolumn{1}{c}{ Group Completion } & $\begin{array}{c}\text { Narrow Response } \\
\text { n (\% of Total) }\end{array}$ & $\begin{array}{c}\text { Typical Response } \\
\text { n (\% of Total) }\end{array}$ \\
\hline Pretest & $16(14 \%)$ & $100(86 \%)$ \\
Posttest & $13(12 \%)$ & $100(88 \%)$ \\
\hline Individual completion & & $13(87 \%)$ \\
\hline Pretest & $2(13 \%)$ & $15(100 \%)$ \\
Posttest & $0(0 \%)$ & \\
\hline
\end{tabular}

For part (a), a narrow response might suggest that data must be numerical such as, "the numbers collected in an experiment." A typical response for part (a) would be, "Data is information gathered from an experiment through observation and can be quantitative or qualitative."

Students were asked in part (b) of this question, "Is 'data' the same or different from 'evidence'?"

Table 3: Number Of Responses To Question 2 (b)

\begin{tabular}{lccc}
\hline Group Completion & $\begin{array}{c}\text { Same } \\
\text { n (\% of Total) }\end{array}$ & $\begin{array}{c}\text { Different } \\
\text { n (\% of Total) }\end{array}$ & $\begin{array}{c}\text { Similar/Could Be/Not Sure } \\
\text { n (\% of Total) }\end{array}$ \\
\hline Pretest & $20(17 \%)$ & $77(66 \%)$ & $19(16 \%)$ \\
Posttest & $25(22 \%)$ & $79(70 \%)$ & $9(8 \%)$ \\
\hline Individual completion & & & $1(7 \%)$ \\
\hline Pretest & $3(20 \%)$ & $11(73 \%)$ & $0(0 \%)$ \\
Posttest & $7(47 \%)$ & $8(53 \%)$ & \\
\hline
\end{tabular}




\section{VOSI Question 3}

Question three examines what the students view as an experiment. The question specifically asked, "A person interested in animals looked at hundreds of different types of animals who eat either meat or plants. He noticed that those animals who eat similar types of food tend to have similar teeth structures. For example, he noticed that meat eaters, such as lions and coyotes, tend to have teeth that are sharp and jagged. They have large canines and large, sharp molars. He also noticed that plant eaters, such as deer and horses, have smaller or no canines and broad, lumpy molars. He concluded that there is a relationship between teeth structure and food source in the animals. (a) Do you consider this person's investigation to be an experiment?"

Table 4: Number Of Responses To Question 3(a)

\begin{tabular}{|c|c|c|c|}
\hline Group Completion & $\begin{array}{c}\text { Yes } \\
\text { n (\% of Total) } \\
\end{array}$ & $\begin{array}{c}\text { No } \\
\text { n (\% of Total) } \\
\end{array}$ & $\begin{array}{c}\text { No Answer } \\
\text { n (\% of Total) }\end{array}$ \\
\hline Pretest & $36(31 \%)$ & $80(69 \%)$ & $0(0 \%)$ \\
\hline Posttest & $52(46 \%)$ & $59(52 \%)$ & $2(2 \%)$ \\
\hline \multicolumn{4}{|l|}{ Individual completion } \\
\hline Pretest & $7(47 \%)$ & $8(53 \%)$ & $0(0 \%)$ \\
\hline Posttest & $3(20 \%)$ & $12(80 \%)$ & $0(0 \%)$ \\
\hline
\end{tabular}

Students were asked in part (b) of this question, "Do you consider this person's investigation to be scientific? Please explain why or why not by describing what it means to do something "scientifically."

Table 5: Number Of Responses To Question 3(b)

\begin{tabular}{cccc}
\hline Group Completion & $\begin{array}{c}\text { Yes } \\
\text { n } \text { of Total) }\end{array}$ & $\begin{array}{c}\text { No } \\
\text { n }(\% \text { of Total })\end{array}$ & $\begin{array}{c}\text { No answer } \\
\text { n } \% \text { of Total })\end{array}$ \\
\hline Pretest & $82(71 \%)$ & $34(29 \%)$ & $0(0 \%)$ \\
Posttest & $68(60 \%)$ & $45(40 \%)$ & $1(1 \%)$ \\
\hline Individual completion & & & $0(0 \%)$ \\
\hline Pretest & $8(53 \%)$ & $7(47 \%)$ & $0(0 \%)$ \\
Posttest & $11(73 \%)$ & $4(27 \%)$ & \\
\hline
\end{tabular}

The study described here is not a conventional experiment in that it does not manipulate a single variable while keeping all the others the same, so the desired response for part (a) shown in table 4 is "No." This constitutes an observational study. Part (b) examines whether students regard this as a scientific study, and the desired response shown in table 5 is "Yes." A respondent with a more narrow view of how science is done would be more likely to say that it is not scientific because only one way to do the scientific method exists, and that requires an experiment (Sibbernsen, 2010).

\section{VOSI Question 4}

This question directly examines the viewpoint of "the scientific method" and follows directly from question three. If responding students specify that the only way to do science is through the scientific method, they describe the method of asking questions, performing an experiment, analyzing information gathered, and coming to a conclusion. The more inclusive description of the scientific method suggests that good science can be conducted in many ways and includes observational and descriptive studies. The students were specifically asked, "The 'scientific method' is often described as involving the steps of making a hypothesis, identifying variables (dependent/independent), designing an experiment, collecting data, reporting results. Do you agree that to do good science, scientists must follow the scientific method?"

Table 6: Number Of Responses To Question 4

\begin{tabular}{cccc}
\hline Group Completion & $\begin{array}{c}\text { Yes } \\
\text { n }(\% \text { Total })\end{array}$ & $\begin{array}{c}\text { No } \\
\text { n (\% Total) }\end{array}$ & $\begin{array}{c}\text { No Answer } \\
\text { n } \% \text { of Total })\end{array}$ \\
\hline Pretest & $83(72 \%)$ & $33(28 \%)$ & $0(0 \%)$ \\
Posttest & $82(73 \%)$ & $30(27 \%)$ & $1(1 \%)$ \\
\hline Individual completion & & & $1(7 \%)$ \\
\hline Pretest & $13(87 \%)$ & $1(7 \%)$ & $0(0 \%)$ \\
Posttest & $14(93 \%)$ & $1(7 \%)$ & \\
\hline
\end{tabular}

Copyright by author(s); CC-BY 


\section{VOSI Question 5}

This question examines the respondents' views of how scientists justify their findings. This question specifically asked, "What type of information is required for scientists to justify and accept a scientific claim? (In other words, how do scientists know when they are ready to make their research results public? What do they need in order to convince others of their claim?)"

Table 7: Number Of Responses To Question 5

\begin{tabular}{|c|c|c|c|}
\hline Group Completion & $\begin{array}{c}\text { Naïve } \\
\text { n }(\% \text { of Total })\end{array}$ & $\begin{array}{c}\text { Typical/informed responses } \\
\text { n (\% of Total) }\end{array}$ & $\begin{array}{c}\text { Other/not sure/blank } \\
\text { n (\% of Total) }\end{array}$ \\
\hline Pretest & $60(52 \%)$ & $54(47 \%)$ & $2(2 \%)$ \\
\hline Posttest & $48(42 \%)$ & $64(57 \%)$ & $1(1 \%)$ \\
\hline \multicolumn{4}{|l|}{ Individual completion } \\
\hline Pretest & $7(47 \%)$ & $7(47 \%)$ & $1(7 \%)$ \\
\hline Posttest & $4(27 \%)$ & $11(73 \%)$ & $0(0 \%)$ \\
\hline Frequency of Terms or Phrases Used & & Pretest & Posttest \\
\hline Repeatable & & 51 & 61 \\
\hline Data/statistics & & 38 & 48 \\
\hline Evidence/proof & & 37 & 58 \\
\hline Publish/peer review & & 37 & 43 \\
\hline Reliability/validity & & 25 & 10 \\
\hline
\end{tabular}

An example of a naïve response to this question would be, "They would need good, solid data in order to prove or disprove their theory." A typical response would include discussions of reliability, validity, evidence, proof, if the data are consistent, repeatable, and if the assertion is falsifiable. Informed responses might include all of these and discuss the need for peer review, collaborative work with other scientists, and publishing or presenting their work at conventions.

\section{VOSI Question 6}

This question probes the understanding of interpretation in data analysis to reach conclusions. Students were asked in part (a), "If several scientists, working independently, ask the same question and follow the same procedures to collect data, will they necessarily come to the same conclusions?"

Table 8: Number Of Responses To Question 6(a)

\begin{tabular}{cccc}
\hline Group Completion & $\begin{array}{c}\text { Same } \\
\text { n }(\% \text { of Total })\end{array}$ & $\begin{array}{c}\text { Different } \\
\text { n (\% of Total) }\end{array}$ & $\begin{array}{c}\text { Maybe/Depends/Blank } \\
\text { n (\% of Total) }\end{array}$ \\
\hline Pretest & $15(13 \%)$ & $93(80 \%)$ & $8(7 \%)$ \\
Posttest & $28(25 \%)$ & $78(69 \%)$ & $7(6 \%)$ \\
\hline Individual completion & & & $1(7 \%)$ \\
\hline Pretest & $2(13 \%)$ & $12(80 \%)$ & $0(0 \%)$ \\
Posttest & $5(33 \%)$ & $10(67 \%)$ & \\
\hline
\end{tabular}

A more nuanced understanding would suggest that some subjectivity must be taken into account in the analysis of similar data while still producing valid conclusions. A naïve response would state that they should get the same results unless one of them made a mistake in his/her analysis. Some respondents replied that they should get the same answers because the underlying physical processes should be the same regardless of the procedure, and others responded that they should get the same results because they are analyzing the same or similar data and suggests that there is no subjectivity in the interpretation.

For part (b) of this question, students were asked, "If several scientists, working independently, ask the same question and follow different procedures to collect data, will they necessarily come to the same conclusions?" 
Table 9: Number Of Responses To Question 6(b)

\begin{tabular}{lccc}
\hline Group completion & $\begin{array}{c}\text { Same } \\
\text { n (\% of Total) }\end{array}$ & $\begin{array}{c}\text { Different } \\
\text { n (\% of Total) }\end{array}$ & $\begin{array}{c}\text { Maybe/Depends/Blank } \\
\text { n (\% of Total) }\end{array}$ \\
\hline Pretest & $4(3 \%)$ & $88(76 \%)$ & $24(21 \%)$ \\
Posttest & $8(7 \%)$ & $95(84 \%)$ & $9(8 \%)$ \\
\hline Individual completion & & & $3(20 \%)$ \\
\hline Pretest & $0(0 \%)$ & $12(75 \%)$ & $1(7 \%)$ \\
Posttest & $0(0 \%)$ & $14(93 \%)$ & \\
\hline
\end{tabular}

Parts (c) and (d) ask if the answers to (a) and (b) should be the same or different if the scientists work together. In general, they could possibly get different results, but it is more likely that a consensus will be reached. Students were asked in part (c), "Does your response to (a) change if the scientists are working together?"

Table 10: Number Of Responses To Question 6(c)

\begin{tabular}{lccc}
\hline Group completion & $\begin{array}{c}\text { Same } \\
\text { n (\% of Total) }\end{array}$ & $\begin{array}{c}\text { Different } \\
\text { n \% of Total) }\end{array}$ & $\begin{array}{c}\text { Maybe/depends/blank } \\
\text { n (\% of Total) }\end{array}$ \\
\hline Pretest & $43(37 \%)$ & $55(47 \%)$ & $18(16 \%)$ \\
Posttest & $53(47 \%)$ & $54(48 \%)$ & $6(5 \%)$ \\
\hline Individual completion & & & $2(13 \%)$ \\
\hline Pretest & $7(47 \%)$ & $6(40 \%)$ & $1(7 \%)$ \\
Posttest & $6(40 \%)$ & $8(53 \%)$ & \\
\hline
\end{tabular}

Students were asked in part (d), "Does your response to (b) change if the scientists are working together?"

Table 11: Number Of Responses To Question 6(d)

\begin{tabular}{lccc}
\hline Group completion & $\begin{array}{c}\text { Same } \\
\text { n (\% of Total) }\end{array}$ & $\begin{array}{c}\text { Different } \\
\text { n (\% of Total) }\end{array}$ & $\begin{array}{c}\text { Maybe/depends/blank } \\
\text { n }(\% \text { of Total) }\end{array}$ \\
\hline Pretest & $27(23 \%)$ & $73(64 \%)$ & $16(13 \%)$ \\
Posttest & $24(17 \%)$ & $79(70 \%)$ & $15(13 \%)$ \\
\hline Individual completion & & & $1(7 \%)$ \\
\hline Pretest & $3(20 \%)$ & $11(73 \%)$ & $1(7 \%)$ \\
Posttest & $3(20 \%)$ & $11(73 \%)$ & \\
\hline
\end{tabular}

\section{VOSI Question 7}

The last question examines how respondents view outliers or inconsistencies in the data. Students were specifically asked, "Occasionally, scientists encounter inconsistencies in their data. What do you think scientists do when some part of their data does not fit with what they expect (an 'outlier' or inconsistency is found)?"

Table 12: Number Of Responses To Question 7

\begin{tabular}{|c|c|c|c|c|}
\hline Group completion & $\begin{array}{c}\text { Naïve } \\
\text { n (\% of Total) }\end{array}$ & $\begin{array}{c}\text { Typical response } \\
\text { n (\% of Total) }\end{array}$ & $\begin{array}{l}\text { Informed view } \\
\text { n (\% of Total) }\end{array}$ & $\begin{array}{c}\text { Blank } \\
\text { n (\% of Total })\end{array}$ \\
\hline Pretest & $20(17 \%)$ & $83(72 \%)$ & $10(7 \%)$ & $1(1 \%)$ \\
\hline Posttest & $15(13 \%)$ & $87(77 \%)$ & $8(7 \%)$ & $3(3 \%)$ \\
\hline \multicolumn{5}{|l|}{ Individual completion } \\
\hline Pretest & $2(13 \%)$ & $12(80 \%)$ & $0(0 \%)$ & $1(7 \%)$ \\
\hline Posttest & $1(7 \%)$ & $13(87 \%)$ & $1(7 \%)$ & $0(0 \%)$ \\
\hline \multicolumn{2}{|c|}{ Frequency of Terms or Phrases Used } & Pretest & \multicolumn{2}{|r|}{ Posttest } \\
\hline \multicolumn{2}{|l|}{ Redo/try again } & 46 & \multicolumn{2}{|r|}{53} \\
\hline \multicolumn{2}{|l|}{ Fix/find what is wrong } & 36 & \multicolumn{2}{|r|}{38} \\
\hline \multicolumn{2}{|c|}{ Revise/adjust/different tests } & 16 & \multicolumn{2}{|r|}{24} \\
\hline \multicolumn{2}{|c|}{ Throw it out/disregard } & 19 & \multicolumn{2}{|r|}{30} \\
\hline \multicolumn{2}{|l|}{ New discoveries } & 9 & \multicolumn{2}{|r|}{8} \\
\hline
\end{tabular}

An example of a naïve response would be, "They don't take it into account and record it as a miss done [sic] experiment using no data from it." A typical response is that, "They should repeat the experiment to find out 
where the mistake is made." Even though this is the typical response, thinking of anomalies as being caused by a mistake in the experiment lacks desirability. An informed view might suggest that the anomalies could lead to new experiments and new discoveries.

\section{Quantitative - Laboratory Exercise Data}

A non-authoring college astronomy professor from another campus who was not teaching the participants study classes volunteered to do the qualitative analysis without knowing the individual students in the study. This expert who performed the grading was deeply familiar with the content and was qualified to assess the quality of the laboratory exercises performed the grading. Only the open inquiry phases of laboratory exercises were evaluated because this was the final phase and a culmination of all of the steps: the development of a research question, producing a procedure, taking the data, and presenting a conclusion.

A two-group unpaired $t$-test was applied to the first week laboratory exercise scores for the individual condition and the collaborative learning group condition to see if a statistical difference could be identified between them. Likewise, a two-group unpaired $t$-test was applied to the last week laboratory exercises scores for the two conditions. The mean scores for the two conditions differ significantly for the first week scores and for the final week scores. These $t$-tests are deemed appropriate because each of the four data sets satisfies the assumptions of normality for each as shown by the Kolmorgorov-Smirnov (Stephens, 1974) comparison of data sets, and each of the pairs of data sets satisfies the assumption of equality of variances as shown by the Bartlett Test (Snedecor \& Cochran, 1989).

Table 13: Laboratory Exercise Scores Two-Group Unpaired $t$-tests

\begin{tabular}{lcccc}
\hline \multicolumn{1}{c}{ Statistics } & $\begin{array}{c}\text { Individuals } \\
\text { First Week }\end{array}$ & $\begin{array}{c}\text { Groups } \\
\text { First Week }\end{array}$ & $\begin{array}{c}\text { Individuals } \\
\text { Last Week }\end{array}$ & $\begin{array}{c}\text { Groups } \\
\text { Last Week }\end{array}$ \\
\hline Mean & 21.42 & 19.72 & 22.50 & 24.28 \\
Standard Dev. & 3.78 & 3.37 & 2.11 & 2.70 \\
\hline$t$-value & & 1.3784 & & 2.0033 \\
Two-tailed p-value & & 0.1768 & 0.0529 \\
$t$-test decision $(\mathrm{p}<.05)$ & Difference is not statistically significant & Difference is not statistically significant \\
\hline
\end{tabular}

A paired $t$-test was performed for the group exercises to see if a significant increase became apparent in the scores from the first week to the last week of laboratory exercises.

Table 14: Laboratory Exercise Group Scores Paired $t$-test

\begin{tabular}{lc}
\hline \multicolumn{1}{c}{ Degrees of Freedom } & $\mathbf{2 4}$ \\
$t$-value & 5.9862 \\
Two-tailed $p$-value & $<0.0001$ \\
$t$-test decision $(p<0.05)$ & Statistically Significant \\
\hline
\end{tabular}

\section{DISCUSSION}

\section{Qualitative - VOSI}

The VOSI allows evaluation of several components of the understanding of scientific inquiry. In general, the results indicate that students' understanding of scientific inquiry increased for some of the questions and remained unchanged for others. More specifically, for the questions that correspond to activities in the focus of the astronomy laboratory, the students appear more comfortable and more adept with the language of science and inquiry, and generally show a greater and nuanced understanding of those processes. 
Table 15: Summary Of VOSI Results

\begin{tabular}{|l|c|c|}
\hline \multicolumn{1}{|c|}{ VOSI } & Groups & Individuals \\
\hline Question 1 - How do scientists do their work? & Increase & Slight Increase \\
\hline Question 2 - Data vs. Evidence & Slight Increase & Slight Increase \\
\hline Question 3 - Is a process scientific or not? & Slight Decrease & No Change \\
\hline Question 4 - Follow the scientific method? & No Change & Increase \\
\hline Question 5 - Scientists justifying claims & Increase & Slight Increase \\
\hline Question 6 - Conclusions working independently & Slight Increase & Slight Increase \\
\hline Question 7 - Outliers & Slight Increase & \\
\hline
\end{tabular}

For both the group and individual conditions, there occurred a large increase in the percentage of students who understood how scientists do science (question 1), a moderate increase in the percentage of students who understood how scientists justify and accept their claims (question 5), and a slight increase in the percentage of students who increased their knowledge of how scientists deal with outlying data points (question 7). For all of these increases, students working individually did as well as the students working in self-formed, small, collaborative learning groups in terms of giving typical or informed responses rather than naïve ones. These three questions acted, arguably, as the most important in terms of understanding scientific inquiry, and were the primary focus of the laboratory exercises.

Very little change occurred (questions 2, 4, and 6), or mixed trends became identifiable (question 3) between the two conditions in the remaining questions. For example, in question two, part (a), only a small portion (about 13\%) of respondents gave a narrow response to the question of what "data" means in science, and this percentage remained relatively unchanged in the posttest for both conditions. This percentage can be interpreted as unexpectedly high in relation to respondents who understood the difference before the course began.

\section{Qualitative - Independent Grader and Instructor Interview}

Although the first and the last week laboratory exercises focused on different core astronomy concepts, the independent expert evaluator judged the quality of inquiry in the last week as better than the first week. The instructor judged that the students grew in their ability to think critically. The VOSI analysis supports this perception.

One particularly interesting feature of the instructor's field notes stands out above all others. Students working as individuals, as compared to their counterparts who were working in groups when completing the BFS laboratory exercises, wrote more than the groups, took longer to do the labs, and designed conservative research questions that were "safer." The instructor generalized that three types of groups tend to develop: equal participation among all members, a group of three with one student quieter but still participating, and a group of three with one student quieter and not participating as much. In the follow-up questions with the instructor, it was suggested that the groups had an advantage over the individuals because of the division of labor, and that if there was no time constraint on the lab, this may not have as much of an effect. No more details are available on this aspect as it was not an anticipated result, and future studies could benefit if this became a focus of further investigation.

\section{Quantitative - Graded Laboratory Exercises}

Laboratory exercises were collected the first week and the last week to determine the probability of an increase in the scores as determined by an inquiry-based rubric (Sibbernsen, 2010). The first week to last week paired exercise $t$-test scores determined that the difference in averages for the group condition was strongly statistically significant with a $p$-value less than 0.0001 . This indicates that they performed better on inquiry during the last week as opposed to the first.

The individuals' average scores also increased from the first to the last week. As opposed to 25 groups with paired scores from the first to the last week, the individual scores could only be paired for 12 of the individuals. The individual condition had a higher mean score in the first week, 21.42, compared to 19.72 for the group condition. From classroom observations, this may be because the individuals spent more time and took more care with writing 
their laboratory exercises at the beginning. The group condition had a higher mean for the last week exercises, 24.28 compared to 22.50 , but these did not differ statistically from each other.

\section{CONCLUSIONS}

The VOSI survey functioned as an effective tool for analyzing and understanding students' developing sense of scientific inquiry. Given that the participating students were largely Caucasian and of traditional college student age, a fruitful future study could be expanded to include different populations using this instrument as a pretest/posttest and could include observations made throughout the semester. The composition of the sample is a potential limitation for generalizing the results of this study across diverse populations. Accordingly, further testing varying the sample and expanding the analysis is recommended. The results from this study that used four-year university students could be compared to a sample of two-year community college students. In addition, the demographics were not considered in this study. Further studies could examine differences between male and female students, different ages, different learning preferences for working individually or in groups, and racial and ethnic differences.

An additional avenue for future study is to perform the pre/post test VOSI for lecture-only astronomy classes to isolate the potentiality of this astronomy laboratory being solely responsible for the increase in understanding of scientific inquiry. A further extension of this work would be to administer the VOSI to students performing the inquiry-based BFS astronomy exercises in an online laboratory situation. Even if students in this situation were allowed to select whether they do the exercises individually or in groups, it is anticipated that most of these students will choose to perform the experiments individually given the challenges of group work in the online environment.

The success of the BFS technique for teaching inquiry has been demonstrated and should translate to sciences other than astronomy, such as geology or physics. Per recommendation, workshops should be held for interested instructors to obtain training on the technique to develop new backwards faded scaffolding inquiry-based laboratory exercises and to learn how to test and analyze students' increase in understanding of inquiry. From these workshops, networks of faculty teaching-participants could be built to share produced materials.

\section{AUTHOR INFORMATION}

Dr. Kendra J. Sibbernsen teaches physics and astronomy at Metropolitan Community College in Omaha, Nebraska. Her research interests focus on areas of developing and implementing inquiry-based laboratories, online learning, and using mobile devices to study science. She also promotes undergraduate research through high altitude balloon launches and the study of cosmic rays. E-mail: ksibb@cox.net

\section{REFERENCES}

American Association for the Advancement of Science (1993). Benchmarks for Scientific Literacy. Retrieved from http://www.project2061.org/publications

American Association for the Advancement of Science (1990). Science for All Americans: Project 2061. New York: Oxford University Press. Retrieved from http://www.project2061.org/publications/sfaa/online/sfaatoc.htm

Fraknoi, A. (2001). Enrollments in astronomy 101 courses. Astronomy Education Review, 1(1), 121-123.

Harwood, W. (2004). A new model for inquiry: Is the scientific method dead? Journal of College Science Teaching, $33(7), 29$.

Johnson, R. B., \& Onwuegbuzie, A. J. (2004). Mixed methods research: A research paradigm whose time has come. Educational Researcher, 33(7), 14-26.

Lawrenz, F., Huffman, D., \& Appeldoorn, K. (2005). Enhancing the instructional environment: Optimal learning in introductory science classes. Journal of College Science Teaching, 34(7), 40.

Lyons, D. J. (2011). Impact of backwards faded scaffolding approach to inquiry-based astronomy laboratory experiences on undergraduate non-science majors' views of scientific inquiry. Ph.D. Dissertation University of Wyoming, 72-12, 4503A. 
National Research Council. (2005). America's Lab Report: Investigations in High School Science. Edited by H.A. Schweingruber, M.L. Hilton, \& S.R. Singer. National Academies Press.

Schwartz, R. S. (2004). Epistemological views in authentic science practice: A cross-discipline comparison of scientists' views of nature of science and scientific inquiry. Ph.D. Dissertation, Oregon State University. Retrieved January 28, 2009 from Dissertations \& Theses: Full Text database. (Publication No. AAT 3138483)

Schwartz, R. S., Lederman, N. G., \& Lederman, J. S. (2008, March). An instrument to assess views of scientific inquiry: The VOSI questionnaire. Annual meeting of the National Association for Research in Science Teaching, Baltimore, MD. Retrieved from http://homepages.wmich.edu/ rschwart/docs/VOSInarst08.pdf

Sibbernsen, K. J. (2010). The impact of collaborative groups versus individuals in undergraduate inquiry-based astronomy laboratory learning exercises. Ph.D. Dissertation, Capella University. Dissertation Abstracts International, 71(5).

Slater, S. J., Slater, T. F. \& Lyons, D. J. (2010). Engaging in astronomical inquiry. New York: WH Freeman.

Slater, S. J., Slater, T. F. \& Lyons, D. J. (2011). Teaching scientific inquiry with Galaxy Zoo. The Physics Teacher, 49(2), 94-96.

Slater, S. J., Slater, T. F. \& Shaner, A. (2008). Impact of backwards faded scaffolding in an astronomy course for pre-service elementary teachers based on inquiry. Journal of Geoscience Education, 56(5), 408.

Snedecor, G. W. \& Cochran, W. G. (1989), Statistical methods, ( ${ }^{\text {th }}$ Ed.). Iowa State University Press.

Stephens, M. A. (1974). EDF statistics for goodness of fit and some comparisons. Journal of the American Statistical Association 69(347), 730-737.

Stewart, S. A. (2013). The design, enactment, and impact of an inquiry-based undergraduate astronomy laboratory learning environment.Ph.D. Dissertation, Syracuse University. Retrieved from http://surface.syr.edu/scied_etd/25/

Society of College Science Teachers, SCST (1993). Introductory Science Courses: The SCST Position Statement. Journal of College Science Teaching, 23(1), 29-31. Retrieved from http://www.scst.org/SCST/Publications_files/Statement20on\%20Courses.pdf 


\section{NOTES}

